\title{
Novel Water Treatment Processes Based on Hybrid Membrane-Ozonation Systems: A Novel Ceramic Membrane Contactor for Bubbleless Ozonation of Emerging Micropollutants
}

\author{
Stylianos K. Stylianou, Katarzyna Szymanska, \\ Ioannis A. Katsoyiannis, and Anastasios I. Zouboulis \\ Division of Chemical Technology, Department of Chemistry, Aristotle University of Thessaloniki, 54124 Thessaloniki, Greece \\ Correspondence should be addressed to Ioannis A. Katsoyiannis; katsogia@chem.auth.gr
}

Received 12 January 2015; Accepted 27 February 2015

Academic Editor: Mostafa Khajeh

Copyright (C) 2015 Stylianos K. Stylianou et al. This is an open access article distributed under the Creative Commons Attribution License, which permits unrestricted use, distribution, and reproduction in any medium, provided the original work is properly cited.

\begin{abstract}
The aim of this study is the presentation of novel water treatment systems based on ozonation combined with ceramic membranes for the treatment of refractory organic compounds found in natural water sources such as groundwater. This includes, firstly, a short review of possible membrane based hybrid processes for water treatment from various sources. Several practical and theoretical aspects for the application of hybrid membrane-ozonation systems are discussed, along with theoretical background regarding the transformation of target organic pollutants by ozone. Next, a novel ceramic membrane contactor, bringing into contact the gas phase (ozone) and water phase without the creation of bubbles (bubbleless ozonation), is presented. Experimental data showing the membrane contactor efficiency for oxidation of atrazine, endosulfan, and methyl tert-butyl ether (MTBE) are shown and discussed. Almost complete endosulfan degradation was achieved with the use of the ceramic contactor, whereas atrazine degradation higher than $50 \%$ could not be achieved even after $60 \mathrm{~min}$ of reaction time. Single ozonation of water containing MTBE could not result in a significant MTBE degradation. MTBE mineralization by $\mathrm{O}_{3} / \mathrm{H}_{2} \mathrm{O}_{2}$ combination increased at higher $\mathrm{pH}$ values and $\mathrm{O}_{3} / \mathrm{H}_{2} \mathrm{O}_{2}$ molar ratio of 0.2 reaching a maximum of around $65 \%$.
\end{abstract}

\section{Introduction}

(1) Organic Compounds and Emerging Pollutants in Water Sources. The degradation of water quality is a matter of major concern worldwide. New synthetic chemical compounds originating from either point (industries, wastewater treatment plants, etc.) or no-point (agriculture, etc.) sources, generally called as emerging pollutants, have been identified at relatively high concentrations in both surface and underground waters [1-3].

Major sources of organic pollutants are industries and municipalities utilizing large quantities of chemicals in the manufacturing processes and in consumer products, respectively. About 300 million tons of synthetic components are used annually and partially find their way in natural waters. Synthetic organic compounds (SOCs) are commonly found in water bodies at low concentrations at the range of 1$1000 \mu \mathrm{g} / \mathrm{L}$ but cause significant health problems to humans. Some examples of SOCs found in water and wastewaters are benzene, dichlorobenzenes, methyl tert-butyl ether (MTBE), toluene, and xylenes. Personal care products (PCPs) find their way to natural waters mostly through urban wastewaters and spread through the water cycle. Some common examples of PCPs found in water are caffeine, trimethoprim, sulfamethoxazole, carbamazepine, and diclofenac. In addition, emerging organic compounds may also come into waters from agriculture sources. Several tons of pesticides and herbicides are annually applied in agriculture and are distributed over a large acreage. Some examples of herbicides originating from human activities found in water bodies are atrazine, endosulfan cyanazine, and metribuzin [4]. 
During the last decades, the construction of many water/wastewater treatment plants has given a solution to conventional water pollution problems; however, the removal of nonbiodegradable compounds, such as atrazine, diclofenac, and benzene, requires specific/supplementary treatment [5-7]. To address this, application of novel membrane processes and advanced oxidation processes has been designed, tested, and applied and can give effective and sustainable solution to this alarming situation.

The objectives of the present work are (a) the presentation of the hybrid membrane processes mainly combined with ozonation, (b) the presentation of an innovative system for applying bubbleless ozonation via ceramic membranes, and (c) the presentation of some results about atrazine, endosulfan, and MTBE oxidation with the use of the ceramic membrane contactor.

(2) Hybrid Membrane Processes. Membranes are widely applied for the treatment of natural waters and wastewaters, with very good results; however, the biggest drawback connected with membrane operation is the membrane fouling, which has to be addressed in order to maintain stable membrane operation. Several methods have been developed in order to limit membrane fouling. The most popular is the use of hybrid processes, which integrate (a) two or more membrane processes and/or (b) membrane processes with other water treatment processes, for example, ozonation, coagulation, sand filtration, applied prior to membrane. The main goals of hybrid processes are to increase the water quality which passes through the membrane, reduce fouling frequency and as a consequence reduce operating costs, minimize environmental pollution risks, and thus make the overall process more efficient [8]. In the following, various hybrid membrane systems recently investigated are introduced and shortly discussed.

(a) Coagulation-Membrane Process. Coagulation is a very common process used as a part of the conventional water treatment train. Usually, it includes several physicochemical processes, such as rapid mixing, slow mixing (flocculation), sedimentation, filtration, and disinfection. The purpose of using coagulants is to increase the size of particles, in order to enable settling or removal by sand or dual layer filtration or membrane filtration. There are two main advantages of coupling coagulation with membrane filtration: enhanced removal of pollutants and reduction of membrane fouling. Coagulation can be coupled with membrane filtration with or without settling. The most conventional way makes use of a flocculation tank and settling to remove flocks from the feed water for the membrane. Another way is based on conveying water directly from flocculation tank to the membrane unit without removal of flocks (direct filtration) [9]. The most recent approach to combine coagulation with MF/UF is based on addition of the coagulant directly into the feed stream prior to membrane without removal of coagulated solids (inline coagulation) [10].

The combination of coagulation with membrane filtration for the treatment of surface waters has been presented by many researchers. Several coagulants have been tested such as chitosan [11], aluminum sulfate, aluminum chloride polyaluminum chloride, ferric chloride [12], and ferric sulfate [13]. All the studies showed that the combination of coagulation with membrane filtration increased the permeate quality when compared with individually operated process and greatly mitigated membrane fouling. Furthermore, coagulation has been tested together with UF membranes in order to remove heavy metal ions such as arsenic and antimony that cannot be retained by UF membrane pores. Removals up to $95 \%$ were achieved with the application of the hybrid processes [14-16]. Alternately to conventional polymeric UF membranes, ceramic membranes can be combined with coagulation in a hybrid system, offering the additional benefit that they provide higher chemical and mechanical stability, reducing the maintenance costs of such a process [17].

(b) Adsorption-Membrane Process. Adsorption is another widely used technology in water treatment, and it can be coupled with membrane filtration. Suspended powders, like PAC (powdered activated carbon), are mainly used in order to remove organic compounds that can be hardly removed by MF or UF membrane processes but can enhance membrane fouling. Similar to the hybrid process of coagulationmembrane filtration, adsorption can be combined with membrane filtration with or without clarification. In general, adsorbents require long contact times or high concentrations in order to make the process effective; hence the adsorbent regeneration can be required in many cases to make the process. It has been reported in the literature that the performance of the hybrid adsorption-membrane process depends on such factors as adsorbent dosing, membrane properties, backwashing frequency, reactor size and configuration, filtration mode, and NOM concentration and characteristics. Several reports indicated that during surface water treatment with membrane processes the addition of absorbents decreased fouling rates [18, 19]. However, the addition of PAC in some cases increased pore blockage depending on membrane and absorbent characteristics [20]. Khan et el. [21] studied the influence of particle size on membrane fouling at a PAC-UF system. In addition, absorption-membrane filtration processes have been tested for the removal of micropollutants such as geosmin [22] and diclofenac [23]. A PAC dosage of around $15 \mathrm{mg} / \mathrm{L}$ was essential to achieve satisfactory removal efficiencies. Another example of a hybrid PAC/UF process for the removal of micropollutants from wastewater treatment plant effluents was presented by Löwenberg et al. [24]. The hybrid process is capable of removing micropollutants in typical concentrations range at a PAC dosage of around $20 \mathrm{mg} / \mathrm{L}$ and with a supporting coagulant dosage $4 \mathrm{mg} / \mathrm{L} \mathrm{Fe}^{3+}$. Also, the UF membranes are well compatible with the application of PAC showing no sign of severe pore blockage.

(c) Ion Exchange-Membrane Process. In the past few years, hybrid processes combining fluidized ion exchange and magnetic ion exchange (MIEX) have been studied. NOM can be removed by nanoporous anion exchange because of the negative charge exhibited by the humic substances. Fluidized ion exchange treatment before UF and NF has been applied 
for surface water treatment by Cornelissen et al. [27], and the removal of $60 \%$ for NOM and $>90 \%$ for humic substances by using UF and NF membranes was achieved, respectively.

(d) Prefiltration-Membrane Process. Prefiltration with use of cartridges, sand, packed bed materials, or other membranes is used as preliminary barriers to remove coarse materials and microorganisms, which can have a detrimental effect on the membrane performance [8]. The main advantage of the membrane prefiltration is connected with its compact and modular design and a small footprint. The granular media filters used as a pretreatment to membrane filtration are able to capture particles of larger size distribution, so both the membrane surface fouling and pore clogging can be reduced. However, the disadvantages of such pretreatment are connected with the fact that such filters can deteriorate and be difficult to recover. Furthermore, to enhance the efficiency of granular filters, pretreatment methods such as precoagulation and/or preoxidation may be required [10].

(3) Oxidation and Disinfection Processes in Water Treatment. The most appropriate method for the transformation of emerging organic micropollutants into less harmful products is the chemical oxidation, as it has the capability of completely destroying the target pollutants. Chemical oxidation methods are typically used in water treatment for the removal of specific inorganic and organic compounds from the treated water such as NOM and PPCPs. Many different types of oxidation processes have been developed depending on their application, but there are three main types of oxidation processes used water treatment that may be distinguished [28]:

(i) conventional oxidation processes: oxidants such as chlorine, chlorine dioxide, or potassium permanganate do not produce reactive species such as hydroxyl radicals;

(ii) oxidation processes at elevated temperatures and/or pressures: these processes are based on free-radical reactions involving the hydroxyl radicals; examples of such processes are wet oxidation, supercritical oxidation, and gas-phase combustion;

(iii) advanced oxidation processes (AOPs): they are based on production of hydroxyl radicals at ambient temperature and atmospheric pressure, that is, $\mathrm{O}_{3} / \mathrm{H}_{2} \mathrm{O}_{2}$, $\mathrm{Fe} / \mathrm{H}_{2} \mathrm{O}_{2}, \mathrm{UV} / \mathrm{H}_{2} \mathrm{O}_{2}, \mathrm{UV} / \mathrm{TiO}_{2}$, and so forth.

The main applications of oxidation processes in water treatment are as follows [29]:

(i) taste and odor control [30]: compounds that cause taste and odor problems in surface and groundwater are organic compounds produced by algal blooms and bacteria (mainly geosmin and 2-methylisoborneol (MIB)), inorganic compounds and mercaptans (organic sulfides), iron, and manganese;

(ii) hydrogen sulfide removal $\left(\mathrm{H}_{2} \mathrm{~S}\right)$ : this compound is present in groundwaters with high concentration of sulfates as a consequence of the activities of sulfur reducing bacteria and is responsible for a specific rotten egg odor; it also increases the corrosiveness of some water to metal and concrete;

(iii) color removal: color of water originating from the nominal organic matter (NOM) is yellow or light brown; it is caused by humic acids and other substances; when chlorine is used for the color removal chlorinated by-products are produced from the reaction of chlorine with NOM [31];

(iv) iron and manganese removal: chlorine, potassium permanganate, ozone, and biological oxidation are mainly used to oxidize and form insoluble products which precipitate and are removed from water;

(v) disinfection: chlorine and ozonation are commonly used for disinfection; sometimes to achieve disinfection together with oxidation, ozone is firstly introduced for disinfection and consequently $\mathrm{H}_{2} \mathrm{O}_{2}$ is added to create hydroxyl radicals in order to increase oxidation reaction kinetics and minimize bromate formation;

(vi) control of biofilm growth and biofouling in treatment processes and distribution system components [32];

(vii) oxidation of selected emerging organic micropollutants such as dioxins, phthalates, and pharmaceuticals [33].

The most common chemical oxidants, which are being used in water treatment, are summarized in Table 1, along with their electrical potential and methods of application [25].

The advanced oxidation has the advantage over conventional oxidation that it generates high concentrations of hydroxyl radical $\left(\mathrm{HO}^{\circ}\right)$, a very strong but not selective oxidant capable of complete oxidation of most organic compounds into carbon dioxide or to less toxic products after sufficient contact time. As hydroxyl radicals are reactive electrophiles, they react rapidly with nearly all electron-rich compounds. The reactions with hydroxyl radical are second order, as the reactions depend both on the concentration of the compound to be oxidized and on the concentration of the hydroxyl radical species. For many dissolved organic compounds the second order hydroxyl radical rate constants are in the order of $10^{8}$ to $10^{9} \mathrm{~L} / \mathrm{mole} * \mathrm{~s}$, which is about three to four orders of magnitude greater than second order rate constants for the other oxidants [25].

The rate constants of hydroxyl radical reaction with some common refractory organic micropollutants are presented in Table 2 [26].

(a) Advantages and Disadvantages of AOPs and Ozonation. AOPs are widely used in water treatment for the removal of specific compounds, that is, pesticides, PCPs, and so forth which are hardly removed by any other conventional water/wastewater treatment methods such as biological treatment.

Advantages of using AOPs in the water treatment are as follows:

(i) they can effectively remove organic pollutants from the aqueous phase, not only separate it; 
TABLE 1: Oxidants, forms, and application methods [25].

\begin{tabular}{|c|c|c|c|c|}
\hline Oxidant & Forms & Applications & Application method & Electrical potential, $\mathrm{V}$ \\
\hline Fluorine & Not used & - & Not used & 3.06 \\
\hline Hydroxyl radical & $\begin{array}{l}\text { Generated in specially designed } \\
\text { reactors at the moment of use due to } \\
\text { short life }\end{array}$ & A, B, C, D & & 2.80 \\
\hline Ozone & $\begin{array}{l}\text { Ozone is a gas that is generated on-site } \\
\text { by passing dry compressed air or pore } \\
\text { oxygen across a high voltage electrode }\end{array}$ & $\mathrm{B}, \mathrm{C}, \mathrm{D}$ & $\begin{array}{l}\text { Ozone is applied to water as a } \\
\text { gas. Because mass transfer is an } \\
\text { important issue, special attention } \\
\text { is required for contractor design }\end{array}$ & 2.08 \\
\hline Peracetic acid & Stabilized liquid solution & A, D & $\begin{array}{l}\text { Concentrated solution mixed } \\
\text { with water to be treated }\end{array}$ & - \\
\hline Hydrogen peroxide & Liquid solution & A & $\begin{array}{l}\text { Concentrated solution mixed } \\
\text { with water to be treated }\end{array}$ & 1.78 \\
\hline Permanganate & Available in bulk as granules & A, B & $\begin{array}{l}\text { Added as a dry chemical using a } \\
\text { feeder or as a concentrated } \\
\text { solution (no more than five } \\
\text { percent by weight due to its } \\
\text { limited solubility) }\end{array}$ & 1.67 \\
\hline Chlorine, free & Chlorine gas, $\mathrm{NaOCl}$ solution & $\mathrm{A}, \mathrm{D}$ & $\begin{array}{l}\text { Gas eductors and various diffuser } \\
\text { designs }\end{array}$ & 1.49 \\
\hline $\begin{array}{l}\text { Chlorine, combined } \\
\text { (chloramines) }\end{array}$ & $\begin{array}{l}\text { Addition of ammonia: anhydrous } \\
\text { ammonia gas, ammonium sulfate, and } \\
\text { aqua ammonia ( } 20 \text { to } 30 \text { percent } \\
\text { ammonia solution) }\end{array}$ & A, D & $\begin{array}{l}\text { Gas eductors, dry chemical } \\
\text { feeders, and spray jets }\end{array}$ & - \\
\hline Chlorine dioxide & $\begin{array}{l}\text { Chlorine dioxide gas is produced } \\
\text { on-site using a } 25 \text { percent sodium } \\
\text { chlorite solution. The sodium chlorite } \\
\text { solution reacts with the following } \\
\text { constituents to form } \mathrm{ClO}_{2(\mathrm{~g})} \text { : }(1) \\
\text { gaseous chlorine }\left(\mathrm{Cl}_{2}\right),(2) \text { aqueous } \\
\text { chlorine (HOCl), or acid (usually } \\
\text { hydrochloric acid, } \mathrm{HCl})\end{array}$ & A & Gas eductors & 1.27 \\
\hline Oxygen & Gas and liquid & - & $\begin{array}{l}\text { Pure oxygen or the oxygen in air } \\
\text { applied using diffusers or other } \\
\text { devices }\end{array}$ & 1.23 \\
\hline
\end{tabular}

$\mathrm{A}=$ oxidation of reduced inorganic species such as soluble metals, complexed metal species, and destruction of odor causing compounds.

$\mathrm{B}=$ oxidation of trace organic compounds, color and odor causing compounds, and NOM.

$\mathrm{C}=$ to improve coagulation.

$\mathrm{D}=$ used as a biocide to control algae in reservoirs and basins, for disinfection, and to control growth in distributions system.

TABLE 2: Rate constants of hydroxyl radical reaction with some common refractory organic micropollutants [26].

\begin{tabular}{lc}
\hline Compound & $k / \mathrm{M}^{-1} \mathrm{~s}^{-1}$ \\
\hline Amidotrizoic acid & $9.8 \times 10^{8}$ \\
Atrazine & $3 \times 10^{9}$ \\
Geosmin & $7.8 \times 10^{9}$ \\
Tetrachloroethene & $2.3 \times 10^{9}$ \\
Iopamidol & $3.3 \times 10^{9}$ \\
Ibuprofen & $7.4 \times 10^{9}$ \\
1,4-Dioxane & $2.5 \times 10^{9}$ \\
\hline
\end{tabular}

(ii) they react with almost every compound present in the water or wastewater treated;

(iii) some of the heavy metals can also be removed in precipitated forms $\mathrm{M}(\mathrm{OH})_{x}$; (iv) a secondary waste stream is not generated and therefore there is also no additional cost for disposal or regeneration of exhausted materials;

(v) AOPs can be conducted at normal temperatures and pressures;

(vi) reducing bromated formation when ozonation is used together with $\mathrm{H}_{2} \mathrm{O}_{2}$.

On the other hand, the drawbacks related to the application of AOPs are as follows:

(i) the high energy consumption and thus the high cost of using AOPs; for example, the combination of $\mathrm{O}_{3} / \mathrm{UV}$ increases the energy requirements by almost $25 \%$ compared to singe ozonation [34];

(ii) AOPs techniques require pretreatment of the wastewater; 
(iii) given the high cost of using AOPs, they may not be individually able to treat a large amount of wastewater; AOPs should be used for the final stage of the water/wastewater treatment.

(b) Major Factors Affecting AOPs. Different chemical and physical properties of the treated water matrix may have a major impact on the effectiveness of AOPs because they can either scavenge hydroxyl radicals or absorb UV light which is necessary for production of hydroxyl radicals from hydrogen peroxide and ozone. Katsoyiannis et al. [34] showed that scavenger concentration has a major effect on required energy consumption and thus cost for micropollutants transformation by $\mathrm{O}_{3}, \mathrm{O}_{3} / \mathrm{H}_{2} \mathrm{O}_{2}$, and $\mathrm{UV} / \mathrm{H}_{2} \mathrm{O}_{2}$. For example, pCBA (p-chlorobenzoic acid) depletion required 50 times higher energy in high scavenger rate waters compared to low ones.

The main factors affecting AOPs are as follows [35]:

(i) carbonate species $\left(\mathrm{HCO}_{3}{ }^{-}\right.$and $\left.\mathrm{CO}_{3}{ }^{2-}\right)$ : they are scavengers of hydroxyl radicals and their presence in the treated water significantly reduces the rate of organic compounds destruction;

(ii) $\mathrm{pH}: \mathrm{pH}$ of the treated solution affects the concentrations of carbonate species; it also affects the rate of $\mathrm{O}_{3}$ decomposition and thus the production of hydroxyl radicals, which is important in the $\mathrm{UV} / \mathrm{H}_{2} \mathrm{O}_{2}, \mathrm{UV}, \mathrm{O}_{3}$, and $\mathrm{H}_{2} \mathrm{O}_{2} / \mathrm{O}_{3}$ AOPs; $\mathrm{pH}$ can also affect the charge on some organic compounds if they are weak acids and bases;

(iii) natural organic matter (NOM): NOM reacts with the hydroxyl radicals and quenches the reaction; thus less quantity is available to transform the target compounds;

(iv) reduced forms of metal ions such as Fe(II) and Mn(II) consume chemical oxidants and scavenge hydroxyl radicals for their oxidation.

(c) By-Products of AOPs. Advanced oxidation processes, including the processes that are based on ozonation, have been found to produce brominated by-products and bromate $\left(\mathrm{BrO}_{3}{ }^{-}\right)$in waters containing bromide ion, a process that has to be mitigated. The quantity of brominated by-products formed during AOPs is determined by the $\mathrm{pH}$, temperature, TOC concentration, and the concentration of bromide ion in the feed water. Bromate production increases with increasing temperature, $\mathrm{O}_{3} / \mathrm{DOC}$ ratio, and bromide feed concentration. Addition of ammonia or hydrogen peroxide and $\mathrm{pH}$ adjustment can be used to minimize the brominated by-products formation. At higher $\mathrm{pH}$ values the scavenging effect of bicarbonates is more efficient because of the higher instability of ozone to produce free radicals. The addition of ammonia prevents the formation of $\mathrm{BrO}_{3}{ }^{-}$by creating bromamines, while the addition of hydrogen peroxide reduces bromated formation because $\mathrm{H}_{2} \mathrm{O}_{2}$ reduces $\mathrm{HOBr}$ to bromide $[36,37]$.

Both hydrogen abstraction and radical addition processes produce reactive organic radicals, which subsequently undergo oxidation and may combine with dissolved oxygen to form peroxy organic radicals $\left(\mathrm{ROO}^{\circ}\right)$. These undergo radical chain reactions, which produce a variety of oxygenated byproducts. The general pattern of oxidation is presented below:

Organic compound $\rightarrow$ Aldehydes $\rightarrow$ Carboxylic acids $\rightarrow$ Carbon dioxide and mineral acids.

Of all the above-mentioned by-products, carboxylic acids are of particular concern, as their second order rate constants with hydroxyl radicals are much lower than for most other organics, thus inhibiting degradation of these constituents [38].

(d) Disinfection By-Products Resulting from Use of Ozone as Disinfectant. One of the major advantages of using ozone is that it does not form chlorinated DBPs (disinfection byproducts) such as THMs and HAAs. However, ozonation does produce other DDBs including aldehydes, various acids, and aldo- and keto acids when significant amounts of bromide are not present in the treated water. When bromide is present, several DBPs may also be produced, such as inorganic bromate ion, bromoform, brominated acetic acid, bromopicrin, brominated acetonitriles, cyanogen bromide, and bromate. The nature and composition of water to be treated and the presence of disinfection by-products precursors determine the specific amounts and relative distribution of produced DBPs.

As the nonbrominated compounds appear to be readily biodegradable, they can be removed by biological filtration. The removal of DBPs is more complex when they are produced in the presence of bromide. Also, it has been reported that ozone residuals can be acutely toxic to aquatic life. Furthermore, it has been reported that ozonation can produce some toxic mutagenic and/or carcinogenic compounds, although these compounds are usually unstable and are present only for a matter of minutes in the ozonated water [26].

The impact of main water constituents on disinfection by ozonation is summarized in Table 3 [25].

Apart from the already established uses of ozone in industry and water treatment, there is considerable interest in using ozone for more specific applications. Using ozone is connected with some challenges, such as the following.

(i) Ozone resistant materials have to be used in systems using ozone, independently of its concentration. Even at low concentrations ozone deteriorates most of the common materials used in water/wastewater treatment plants and so only chemically inert materials can be used such as PTFE, Teflon, and $\mathrm{Al}_{2} \mathrm{O}_{3}$.

(ii) As the production of ozone is a relatively expensive process compared with conventional water/wastewater treatment methods, high consumption of ozone doses added to the systems should be obtained.

(iii) Ozone should be introduced to the treated water in such a way that would enable sufficient ozone/pollutant contact time.

(4) Ceramic Membranes. Ceramic membranes consist of several layers made of one or more ceramic materials; thus 
TABLE 3: Impact of water constituents on the use of ozone for disinfection [25].

\begin{tabular}{ll}
\hline Constituent & Effect \\
\hline BOD, COD, TOC, and so forth & $\begin{array}{l}\text { Organic compounds that comprise the BOD and COD can exert an ozone demand. The } \\
\text { degree of interference depends on their functional groups and their chemical structure }\end{array}$ \\
NOM (natural organic matter) & $\begin{array}{l}\text { Affects the rate of ozone decomposition and the ozone demand } \\
\text { Can exert an ozone demand }\end{array}$ \\
Oil and grease & Increase ozone demand and shielding of embedded bacteria \\
Alkalinity & No or minor effect \\
Hardness & No or minor effect \\
Ammonia & No or minor effect and can react at high pH \\
Nitrite & Oxidized by ozone \\
Nitrate & Can reduce effectiveness of ozone \\
Iron & Oxidized by ozone \\
Manganese & Oxidized by ozone \\
pH & Affects the rate of ozone decomposition \\
Industrial discharges & Depending on the constituents, may lead to diurnal and seasonal variations in the ozone \\
Temperature & demand \\
\hline
\end{tabular}

they are called as composite membranes. Usually they are made of a macroporous support, one or more mesoporous layers, and a microporous (or dense) top layer. At the top layer of the ceramic membrane the separation takes place, while the middle layers bridge the top and the bottom layer, which provide mechanical support. Materials used for production of ceramic membranes are $\mathrm{Al}_{2} \mathrm{O}_{3}, \mathrm{TiO}_{2}, \mathrm{ZrO}_{2}$, and $\mathrm{SiO}_{2}$, or different combinations of them. Commercial ceramic membranes may have several configurations, such as discs, plates, or tubular [39].

Ceramic membranes possess many advantages over conventional polymeric membranes, such as the following [40, 41]:

(i) a relatively narrow pore size distribution and higher porosity around $50 \%$, which has an effect on better separation characteristics and a higher flux;

(ii) considerably higher mechanical stability, which allows application of higher pressures;

(iii) extended backwash intervals and low chemical cleaning required;

(iv) considerably higher chemical stability, which results in longer membrane lifetime and allows applications at wider range of $\mathrm{pH}$ of the treated waters;

(v) higher hydrophilicity, which results in obtaining higher fluxes at lower pressures;

(vi) higher feed water recoveries.

(a) Use of Ceramic Membranes for Bubbleless Ozonation. Conventionally, transfer of $\mathrm{O}_{3}$ into water is mainly carried out via injectors, bubble columns, and gas diffusers. Common feature of all these techniques is the formation of bubbles; however, gas-liquid transport is a rate limiting process, depending on parameters such as the gas bubbles diameter [42]. Such a process almost never results in complete consumption of the ozone added in water. Furthermore, conventional gaswater contactors also suffer from foam creation problems, while when a gas containing ozone is applied, an ozone destructor has to be placed at the end-line in order to destroy the remaining ozone in the off-gas. An alternative approach for addressing these issues is use of membrane as contactors in order to optimize the contact between the gaseous and aqueous phase [43]. This novel application of membranes for the gas-water contacting has only recently gained the interest of environmental scientists $[44,45]$. Studies have shown that hydrophobic membranes offer much higher efficiency of gas liquid contact than hydrophilic [46]. It is due to the fact that water in contact with a hydrophilic membrane is likely to penetrate into the pores due to capillary forces, which causes severe operational problems. The level of capillary pressure in hydrophilic porous media foreseen from theoretical approaches as a function of pore diameters can reach very high values, creating problems with gas transportation [47]. Kukuzaki et al. show that hydrophobized SPG membranes offer an overall mass transfer coefficient of $1.2 \times 10^{-5} \mathrm{~m} \mathrm{~s}^{-1}$, which is much larger than $2.1 \times 10^{-6} \mathrm{~m} \mathrm{~s}^{-1}$ value calculated for hydrophilic membranes [48].

In the previous years polymeric membranes were successfully implemented in water and wastewater treatment, as well as in several industry-related applications, that is, food industry. Additionally, previous studies have demonstrated that the polymeric membranes are not suitable for treatment with harsh chemicals, such as oxidizing agents [49]. As ozone is a highly reactive compound and easily oxidizes organic and polymeric materials, only chemically inert membranes, such as ceramic membranes, can be used for these applications.

To date, little research has been conducted for the use of ceramic membranes for the transfer of ozone without the creation of bubbles (bubbleless ozonation) [50, 51]. In the present study, the operation of a ceramic membrane 
contactor for the transfer of ozone to water contaminated with organic micropollutants was tested. The efficiency of ozone transfer and degradation of atrazine, endosulfan, and MTBE are presented. The objective of the present work therefore is to investigate the possibility of using ceramic in ozonation of partially polluted water.

\section{Materials and Methods}

2.1. Synthetic Feed Water Solutions. Three different aquatic solutions of selected pollutants were used for the testing of AOPs based on ozonation introduced in the water applied via the ceramic membrane contactor. Atrazine and endosulfan solutions at concentrations of $10 \mu \mathrm{g} / \mathrm{L}$ and MTBE solution at concentration of $1 \mathrm{mg} / \mathrm{L}$ in deionized water were used. The selection of the pollutants and the concentrations used in this study to prepare the synthetic solutions were based on recent studies that have identified them in high concentrations in several regions around the world $[1,4,52]$. The reagents used for preparation of the target pollutants solutions were of analytical grade (Fluka). The $\mathrm{pH}$ of all feed water solutions was adjusted at 7.5 by adding small amounts of $1 \mathrm{M} \mathrm{HCl}$ and $\mathrm{NaOH}$ when appropriate. All chemicals used for solutions were of reagent grade and were used as received.

2.2. Ceramic Membrane Specification. Commercially available tubular cross flow ceramic membranes with an asymmetric 3-layer composition were used in the membrane contactor. The first layer of the membrane operates as a support for the other layers, the third layer operates as a microfiltration layer (pore sizes between 100 and $200 \mathrm{~nm}$ ), and the second layer (pore size of $500 \mathrm{~nm}$ ) serves as the bridge between the macroporous support and the microfiltration layer. The used ceramic membranes were made of $\alpha-\mathrm{Al}_{2} \mathrm{O}_{3}$ and were totally ozone resistant. The dimensions of the membranes were as follows: length of $340 \cdot 10^{-3} \mathrm{~m}$, an internal diameter of $8 \times 10^{-3} \mathrm{~m}$, and an external diameter of $14 \times 10^{-3} \mathrm{~m}$. Membrane surfaces were modified via silanes method [45] in order to increase their hydrophobicity in order to avoid the penetration of water into the pores due to capillary forces, resulting in reduced gas transfer efficiency [48]. The ceramic membranes were modified and supplied by the Laboratory of Inorganic Materials, Chemical Process Engineering Research Institute, Center for Research and Technology Hellas, Thessaloniki, Greece.

2.3. Membrane Contactor Module. Figure 1 shows the experimental setup and housing membrane contactor. Vessels housing the ceramic membrane were made of plexiglass and designed in order to ensure air- and water-tight conditions within the module. Ozone resistant materials were used to construct the experimental unit, such as plexiglass, Viton, and PTFE. Within the membrane contactor, the gas phase was introduced outside of the membrane, while the treated water was introduced at the inside of the membrane, and the gas-water contacting was taking place at the membrane inner surface without bubble creation. Low pressure difference, in the range around 0.1 bar, was applied between the gas and

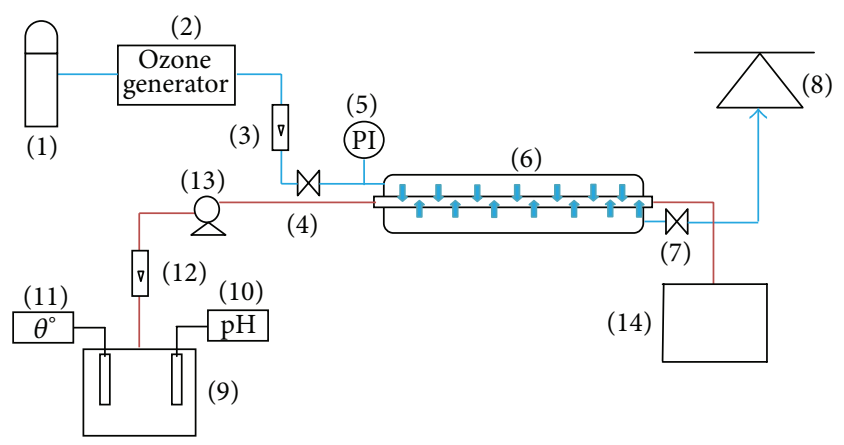

FIGURE 1: Flowchart of the experimental setup used for ozonation experiments: (1) $\mathrm{O}_{2}$ tank, (2) ozone generator, (3) ozone flowmeter, (4) needle valve, (5) pressure transducer, (6) ceramic membrane module (plexiglass), (7) needle valve, (8) air hood, (9) water tank, (10) pH meter, (11) thermometer, (12) water flowmeter, (13) peristaltic pump, and (14) final water tank.

water phases in order to avoid the formation of bubbles, thus minimizing ozone losses. Practically, mix and dispersion phenomena do not occur between the two phases and the transfer of ozone takes place only via diffusion [53].

Ozone-oxygen gas mixture was produced by an ozone generator (model TOGC2A, Ozonia Triogen). Pure oxygen was used as a feed gas with an inlet pressure of 0.5 bar. The pressure of ozone-oxygen gas mixture produced by the ozonator was monitored by a digital pressure meter (WIKA, model S-10). The flow rate of ozone-oxygen gas mixture was measured and adjusted by a flow meter equipped with a needle valve (Aalborg, model PMR-1). In order to control the oxygen-ozone gas mixture flow rate and pressure, before reaching membrane contactor, a by-pass was used. A peristaltic pump (Watson Marlow, model 503U) was used to pump water within the membrane at atmospheric pressure and at various flow rates: Reynolds numbers.

2.4. Analytical Methods. Initial and final samples were collected for the analytical measurements. Sodium bisulfate and indigo trisulfonate purchased from Sigma-Aldrich were used for the termination of ozone and hydroxyl radical reactions at the desired time. Atrazine and endosulfan concentrations were determined by liquid-solid extraction and capillary column gas chromatography/mass spectrometry (EPA method 525.2). Total organic carbon as an indicator of the degree of pollutant mineralization was measured by TOC- $\mathrm{V}_{\mathrm{CSH} / \mathrm{CSN}}$ Total Organic Carbon Analyzer (Shimadzu). Ozone concentrations in the gas phase were determined by the potassium iodide method, while dissolved ozone concentrations were measured with Indigo method [54]. $\mathrm{pH}$ of the solutions was measured with a Jenway pH meter (model 3540).

\section{Results and Discussion}

3.1. Application of Ceramic Membrane Contactor for the Transfer of Ozone to Water. Experiments of ozone transfer to water were conducted with the previously described membrane contactor. Figure 2 presents the dissolved ozone 


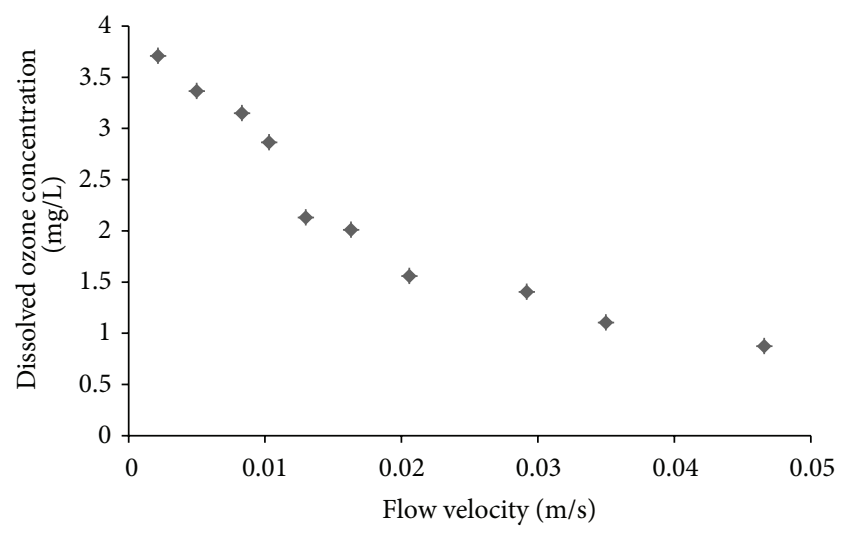

FIGURE 2: Dissolved ozone concentrations as a function of different flow velocities.

concentrations measured in the water leaving the membrane contactor as a function of flow velocity. Dissolved ozone concentrations of up to $3.8 \mathrm{mg} / \mathrm{L}$ were achieved with the use of the ceramic membrane contactor at relatively low flow velocities of around $0.005 \mathrm{~m} / \mathrm{s}$. In addition, almost zero ozone losses to the air phase were identified by KI method, leading to the conclusion that all of the ozone which is reaching the membrane dissolves in water, meaning that bubbleless ozonation was achieved. Overall mass transfer coefficients, $K_{L}$, based on water phase, were calculated [48] and are presented in Figure 3.

Lower mass transfer coefficients were observed with the use of the membrane contactor compared with the conventional techniques, mainly due to the low pressure difference between the two phases and the resistance of the membrane [55]. The decreased mass transfer coefficients together with the relatively high membrane construction cost increase the required investment for the installation of such an ozonation process. However, since complete ozone consumption is achieved, significantly lower operation cost is expected, while the need for an ozone destructor unit in the off-gas is eliminated. Also, increased mass transfer coefficients with increasing Reynolds number were observed, leading to the conclusion that membranes with bigger length and smaller inner diameter will show higher efficiency [48].

\subsection{Application of a Membrane Contactor for the Treatment} of Atrazine and Endosulfan by Ozone Oxidation. Ozonation experiments were conducted with the use of the ceramic membrane contactor in order to evaluate the degradation of atrazine and endosulfan. An ozone dosage of $3 \mathrm{mg} / \mathrm{L}$ of contaminated water was applied by setting a 1.5 min contact time with ozone in the membrane contactor. The residence time of the ozonated water at the final contact chamber was $60 \mathrm{~min}$.

Figure 4 presents changes recorded for the concentrations of atrazine and endosulfan with respect to the residence time. Endosulfan degradation reached almost 100\% after $60 \mathrm{~min}$ while concentrations below $0.1 \mu \mathrm{g} / \mathrm{L}$ were achieved after $30 \mathrm{~min}$ approximately. The concentration of $0.1 \mu \mathrm{g} / \mathrm{L}$ is the highest endosulfan concentration allowed in water according

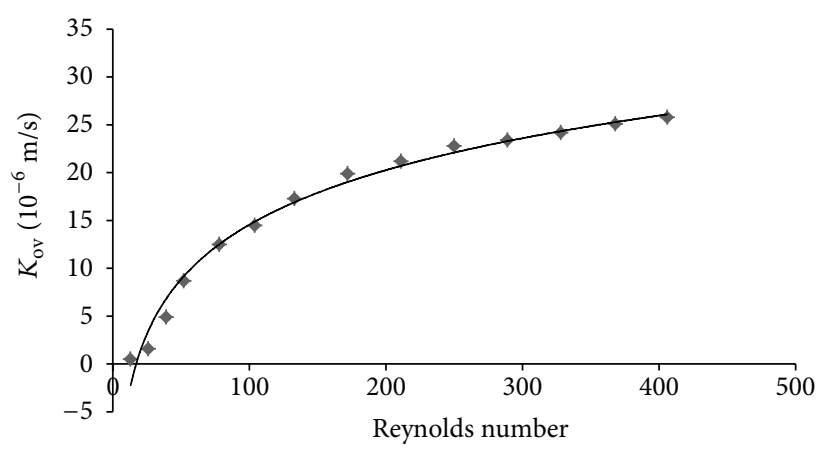

Figure 3: Mass transfer coefficients based on water phase with respect to Reynolds numbers.

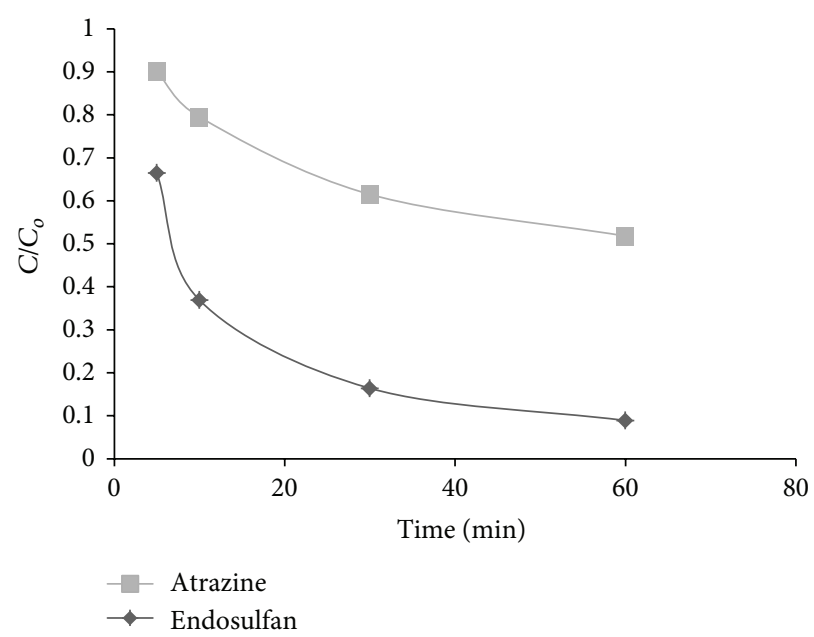

FIGURE 4: Atrazine and endosulfan degradation as a function of residence time.

to the European legislation [56]. The rate of atrazine degradation is much slower than that of endosulfan. Concentrations lower than the respective maximum concentration limits $(0.1 \mu \mathrm{g} / \mathrm{L})$ could not be achieved even after $60 \mathrm{~min}$ reaction time.

TOC measurements as a function of time are presented in Figure 5, which shows that TOC removal reached only $20 \%$ for the case of endosulfan and $10 \%$ for atrazine after 60 minutes reaction time. Several oxidation by-products can be produced during the degradation reactions, and in some cases these by-products can be even more hazardous than the initial compounds, that is, CDIT, DEA, CDAT, methyl cyclohexane, and so forth. Use of $\mathrm{H}_{2} \mathrm{O}_{2}$ will increase the rate of degradation. Second order rate constant of atrazine with $\mathrm{OH}^{-}$is $3 \times 10^{9} \mathrm{M}^{-1} \mathrm{~s}^{-1}$, which is much higher than the $2.3 \mathrm{M}^{-1} \mathrm{~s}^{-1}$ for the reaction with ozone $[57,58]$.

\subsection{Application of a Membrane Contactor for the Treatment} of MTBE by $\mathrm{O}_{3} / \mathrm{H}_{2} \mathrm{O}_{2}$. MTBE solutions were treated by the combination of ozone based oxidation in the presence of hydrogen peroxide, at various experimental conditions (pH: 4-7 and $\mathrm{O}_{3} / \mathrm{H}_{2} \mathrm{O}_{2}$; molar ratios: 0.1-0.4). Feed water 


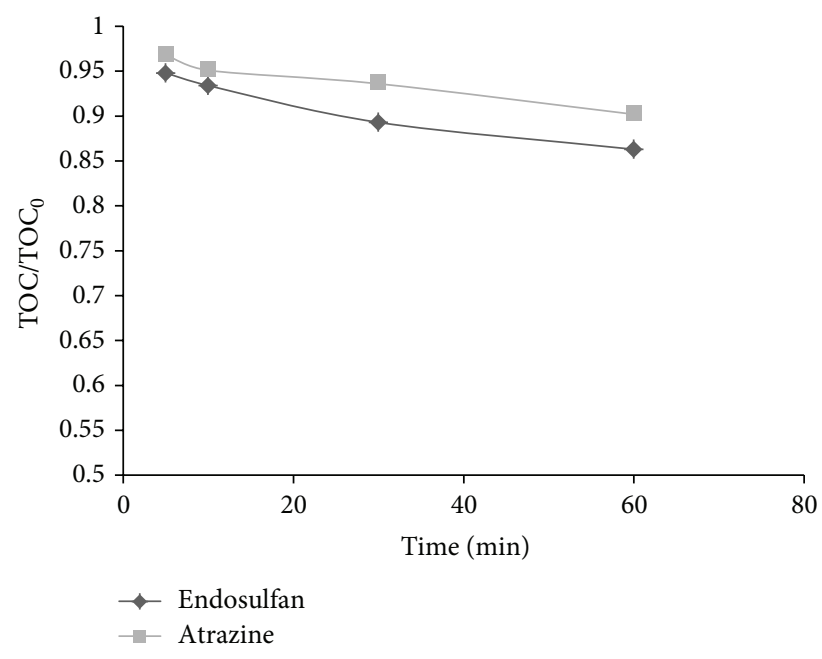

FIGURE 5: TOC reduction during ozonation of atrazine and endosulfan containing solutions.

spiked with MTBE was pumped to the inner surface of the membrane contactor, where the ozone gas transfer took place and was subsequently driven to the final water tank where the hydrogen peroxide solution was added in appropriate doses in order to achieve molar ratios of $\mathrm{O}_{3} / \mathrm{H}_{2} \mathrm{O}_{2}$ in the range from 0.1 to 0.4 . An initial $\mathrm{mol} \mathrm{O}_{3} / \mathrm{mol} \mathrm{MTBE}$ ratio of 50 was used for all the experiments.

Figures 6 and 7 present the results of mineralization of MTBE as a function of time at different $\mathrm{O}_{3} / \mathrm{H}_{2} \mathrm{O}_{2}$ molar ratios and $\mathrm{pH}$, respectively. The obtained results depict that single ozonation could not result in significant MTBE mineralization, but the combination of ozone with hydrogen peroxide resulted in much higher pollutant degradation due to hydroxyl radical's production. The rate constants of the reaction of ozone and $\mathrm{OH}^{*}$ radicals with MTBE have been studied and found to be 0.14 and $1.9 \times 10^{9} \mathrm{M}^{-1} \mathrm{~s}^{-1}$, respectively [59]. TOC measurements indicate that complete MTBE mineralization was never achieved under the present experimental conditions. Ozonation of MTBE is considered as a low rate process, due to the refractory fragments produced during the oxidation [59]. On the other hand, results indicate that the combination of ozone with hydrogen peroxide provides an efficient treatment alternative to MTBE degradation [60]. TOC removal increased at higher $\mathrm{pH}$ values and $\mathrm{O}_{3} / \mathrm{H}_{2} \mathrm{O}_{2}$ molar ratio of 0.2 reaching a maximum of around $65 \%$. Previous studies also indicated that MTBE oxidation is dominated by hydroxyl radical reactions and decay follows pseudo-first order kinetics [61].

\section{Conclusions}

Different approaches for the combination of ceramic membranes and AOPs for emerging pollutants treatment have been presented in the present study and the following conclusions can be drawn.

(i) Dissolved ozone concentrations of up to $3.8 \mathrm{mg} / \mathrm{L}$ were achieved with the use of the ceramic membrane

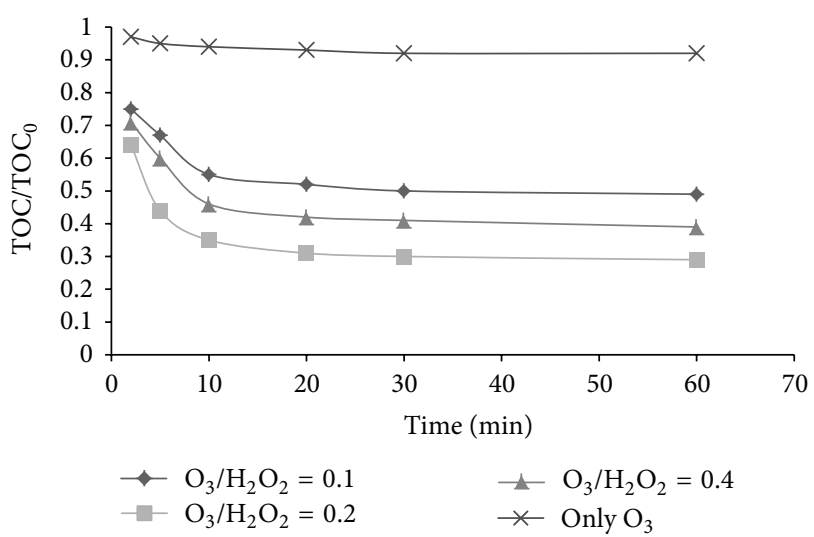

FIGURE 6: TOC reduction during treatment of MTBE containing solution at different $\mathrm{O}_{3} / \mathrm{H}_{2} \mathrm{O}_{2}$ molar ratios.

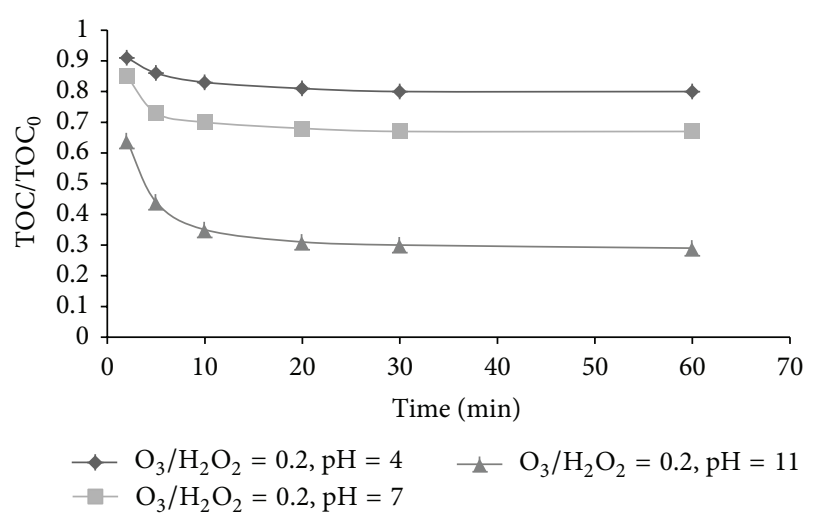

FIGURE 7: TOC reduction during oxidation of MTBE containing water at different $\mathrm{pH}$ values.

contactor at relatively low flow velocities of around $0.005 \mathrm{~m} / \mathrm{s}$.

(ii) Increased mass transfer coefficients with increasing Reynolds number were observed, leading to the conclusion that membranes with bigger length and smaller inner diameter will show higher efficiency.

(iii) The use of membrane contactor for ozonation increases the capital cost of the process but significantly reduces the operational cost by limiting the losses of ozone near zero. Further research is necessary in order to improve the characteristics of the ceramic membranes and to optimize the operation of the membrane contactor.

(iv) Endosulfan concentrations below European maximum concentration limits $(0.1 \mu \mathrm{g} / \mathrm{L})$ were achieved after $30 \mathrm{~min}$ reaction with ozone.

(v) Atrazine degradation is much slower than that of endosulfan. Concentrations lower than the respective maximum concentration limits $(0.1 \mu \mathrm{g} / \mathrm{L})$ could not be achieved even after $60 \mathrm{~min}$ of reaction time.

(vi) Single ozonation could not result in significant MTBE mineralization, but the combination of ozone with 
hydrogen peroxide resulted in much higher pollutant degradation due to hydroxyl radical's production. Mineralization increased at higher $\mathrm{pH}$ values and $\mathrm{O}_{3} / \mathrm{H}_{2} \mathrm{O}_{2}$ molar ratio of 0.2 reaching a maximum of around $65 \%$.

\section{Conflict of Interests}

The authors declare that there is no conflict of interests regarding the publication of this paper.

\section{References}

[1] T. Lekkas, G. Kolokythas, A. Nikolaou et al., "Evaluation of the pollution of the surface waters of Greece from the priority compounds of List II, 76/464/EEC Directive, and other toxic compounds," Environment International, vol. 30, no. 8, pp. 9951007, 2004.

[2] R. Rodil, J. B. Quintana, E. Concha-Graña, P. López-Mahía, S. Muniategui-Lorenzo, and D. Prada-Rodríguez, "Emerging pollutants in sewage, surface and drinking water in Galicia (NW Spain)," Chemosphere, vol. 86, no. 10, pp. 1040-1049, 2012.

[3] R. P. Schwarzenbach, B. I. Escher, K. Fenner et al., "The challenge of micropollutants in aquatic systems," Science, vol. 313, no. 5790, pp. 1072-1077, 2006.

[4] M. Köck-Schulmeyer, M. Villagrasa, M. López de Alda, R. Céspedes-Sánchez, F. Ventura, and D. Barceló, "Occurrence and behavior of pesticides in wastewater treatment plants and their environmental impact," Science of the Total Environment, vol. 458-460, pp. 466-476, 2013.

[5] Y. Luo, W. Guo, H. H. Ngo et al., "A review on the occurrence of micropollutants in the aquatic environment and their fate and removal during wastewater treatment," Science of the Total Environment, vol. 473-474, pp. 619-641, 2014.

[6] M. P. Ormad, N. Miguel, A. Claver, J. M. Matesanz, and J. L. Ovelleiro, "Pesticides removal in the process of drinking water production," Chemosphere, vol. 71, no. 1, pp. 97-106, 2008.

[7] M. L. Farré, S. Pérez, L. Kantiani, and D. Barceló, "Fate and toxicity of emerging pollutants, their metabolites and transformation products in the aquatic environment," TrAC-Trends in Analytical Chemistry, vol. 27, no. 11, pp. 991-1007, 2008.

[8] R. Singh, "Hybrid membrane systems-applications and case studies," in Hybrid Membrane Systems for Water Purification, R. Singh, Ed., chapter 3, pp. 131-196, Elsevier Science, Amsterdam, The Netherlands, 2005.

[9] A. Zouboulis and I. Katsoyiannis, "Removal of arsenates from contaminated water by coagulation-direct filtration," Separation Science and Technology, vol. 37, no. 12, pp. 2859-2873, 2002.

[10] S. Metsämuuronen, M. Sillanpää, A. Bhatnagar, and M. Mänttäri, "Natural organic matter removal from drinking water by membrane technology," Separation and Purification Reviews, vol. 43, no. 1, pp. 1-61, 2014.

[11] R. Bergamasco, L. C. Konradt-Moraes, M. F. Vieira, M. R. Fagundes-Klen, and A. M. S. Vieira, "Performance of a coagulation-ultrafiltration hybrid process for water supply treatment," Chemical Engineering Journal, vol. 166, no. 2, pp. 483-489, 2011.

[12] L. Fiksdal and T. Leiknes, "The effect of coagulation with $\mathrm{MF} / \mathrm{UF}$ membrane filtration for the removal of virus in drinking water," Journal of Membrane Science, vol. 279, no. 1-2, pp. 364371, 2006.

[13] K. Konieczny, D. Sakol, J. Płonka, M. Rajca, and M. Bodzek, "Coagulation-ultrafiltration system for river water treatment," Desalination, vol. 240, no. 1-3, pp. 151-159, 2009.

[14] X. Du, F. Qu, H. Liang et al., "Removal of antimony (III) from polluted surface water using a hybrid coagulation-flocculationultrafiltration (CF-UF) process," Chemical Engineering Journal, vol. 254, pp. 293-301, 2014.

[15] C.-F. Lin, C.-H. Wu, and H.-T. Lai, "Dissolved organic matter and arsenic removal with coupled chitosan/UF operation," Separation and Purification Technology, vol. 60, no. 3, pp. 292298, 2008.

[16] I. A. Katsoyiannis, A. I. Zouboulis, M. Mitrakas, H. W. Althoff, and H. Bartel, "A hybrid system incorporating a pipe reactor and microfiltration for biological iron, manganese and arsenic removal from anaerobic groundwater," Fresenius Environmental Bulletin, vol. 22, no. 12, pp. 3848-3853, 2013.

[17] K. Konieczny, M. Bodzek, and M. Rajca, "A coagulationMF system for water treatment using ceramic membranes," Desalination, vol. 198, no. 1-3, pp. 92-101, 2006.

[18] M. Tomaszewska and S. Mozia, "Removal of organic matter from water by PAC/UF system," Water Research, vol. 36, no. 16, pp. 4137-4143, 2002.

[19] Y. Matsui, H. Hasegawa, K. Ohno et al., "Effects of superpowdered activated carbon pretreatment on coagulation and trans-membrane pressure buildup during microfiltration," Water Research, vol. 43, no. 20, pp. 5160-5170, 2009.

[20] S. Mozia, M. Tomaszewska, and A. W. Morawski, "Studies on the effect of humic acids and phenol on adsorption-ultrafiltration process performance," Water Research, vol. 39, no. 2-3, pp. 501509, 2005.

[21] M. M. T. Khan, S. Takizawa, Z. Lewandowski et al., "Membrane fouling due to dynamic particle size changes in the aerated hybrid PAC-MF system," Journal of Membrane Science, vol. 371, no. 1-2, pp. 99-107, 2011.

[22] C. Kim, S. I. Lee, S. Hwang, M. Cho, H.-S. Kim, and S. H. Noh, "Removal of geosmin and 2-methylisoboneol (2-MIB) by membrane system combined with powdered activated carbon (PAC) for drinking water treatment," Journal of Water Process Engineering, vol. 4, pp. 91-98, 2014.

[23] M. F. N. Secondes, V. Naddeo, V. Belgiorno, and F. Ballesteros, "Removal of emerging contaminants by simultaneous application of membrane ultrafiltration, activated carbon adsorption, and ultrasound irradiation," Journal of Hazardous Materials, vol. 264, pp. 342-349, 2014.

[24] J. Löwenberg, A. Zenker, M. Baggenstos, G. Koch, C. Kazner, and T. Wintgens, "Comparison of two PAC/UF processes for the removal of micropollutants from wastewater treatment plant effluent: process performance and removal efficiency," Water Research, vol. 56, pp. 26-36, 2014.

[25] T. Asano, F. Burton, H. Leverenz, R. Tsuchihashi, and G. Tchobanoglous, Water Reuse: Issues, Technologies, and Applications, McGraw-Hill, 2007.

[26] C. Sonntag and U. von Gunten, Chemistry of Ozone in Water and Wastewater Treatment: From Basic Principles to Applications, IWA Publishing, 2012.

[27] E. R. Cornelissen, D. Chasseriaud, W. G. Siegers, E. F. Beerendonk, and D. van der Kooij, "Effect of anionic fluidized ion 
exchange (FIX) pre-treatment on nanofiltration (NF) membrane fouling," Water Research, vol. 44, no. 10, pp. 3283-3293, 2010.

[28] C. Comninellis, A. Kapalka, S. Malato, S. A. Parsons, I. Poulios, and D. Mantzavinos, "Advanced oxidation processes for water treatment: advances and trends for R\&D," Journal of Chemical Technology \& Biotechnology, vol. 83, no. 6, pp. 769-776, 2008.

[29] MWH, Water Treatment Principles and Design, John Wiley \& Sons, 2005.

[30] A. Peter and U. von Gunten, "Taste and odour problems generated in distribution systems: a case study on the formation of 2,4,6-trichloroanisole," Journal of Water Supply: Research and Technology, vol. 58, no. 6, pp. 386-394, 2009.

[31] K. Szymanska, A. I. Zouboulis, and D. Zamboulis, "Hybrid ozonation-microfiltration system for the treatment of surface water using ceramic membrane," Journal of Membrane Science, vol. 468, pp. 163-171, 2014.

[32] M. Wietz, M. R. Hall, and L. Høj, "Effects of seawater ozonation on biofilm development in aquaculture tanks," Systematic and Applied Microbiology, vol. 32, no. 4, pp. 266-277, 2009.

[33] Y. Lee, L. Kovalova, C. S. McArdell, and U. von Gunten, "Prediction of micropollutant elimination during ozonation of a hospital wastewater effluent," Water Research, vol. 64, pp. 134$148,2014$.

[34] I. A. Katsoyiannis, S. Canonica, and U. von Gunten, "Efficiency and energy requirements for the transformation of organic micropollutants by ozone, $\mathrm{O}_{3} / \mathrm{H}_{2} \mathrm{O}_{2}$ and $\mathrm{UV} / \mathrm{H}_{2} \mathrm{O}_{2}$," Water Research, vol. 45, no. 13, pp. 3811-3822, 2011.

[35] S. Parsons, Advanced Oxidation Processes for Water and Wastewater Treatment, IWA, 2004.

[36] J. P. Croué, B. K. Koudjonou, and B. Legube, "Parameters affecting the formation of bromate ion during ozonation," Ozone: Science and Engineering, vol. 18, no. 1, pp. 1-18, 1996.

[37] U. von Gunten and Y. Oliveras, "Advanced oxidation of bromide-containig waters: bromate formation mechanisms," Environmental Science and Technology, vol. 32, no. 1, pp. 63-70, 1998.

[38] A. Rodríguez, R. Rosal, J. A. Perdigón-Melón et al., OzoneBased Technologies in Water and Wastewater Treatment, The Handbook of Environmental Chemistry, Springer, Berlin, Germany, 2008.

[39] K. Li, Ceramic Membranes for Separation and Reaction, John Wiley \& Sons, New York, NY, USA, 2007.

[40] B. Hofs, J. Ogier, D. Vries, E. F. Beerendonk, and E. R. Cornelissen, "Comparison of ceramic and polymeric membrane permeability and fouling using surface water," Separation and Purification Technology, vol. 79, no. 3, pp. 365-374, 2011.

[41] S. G. Lehman, S. Adham, and L. Liu, "Performance of new generation ceramic membranes using hybrid coagulation pretreatment," Journal of Environmental Engineering and Management, vol. 18, no. 4, pp. 257-260, 2008.

[42] D. S. Pines, K.-N. Min, S. J. Ergas, and D. A. Reckhow, "Investigation of an ozone membrane contactor system," Ozone: Science \& Engineering, vol. 27, no. 3, pp. 209-217, 2005.

[43] P. Janknecht, P. A. Wilderer, C. Picard, A. Larbot, and J. Sarrazin, "Bubble-free ozone contacting with ceramic membranes for wet oxidative treatment," Chemical Engineering \& Technology, vol. 23, no. 8, pp. 674-677, 2000.
[44] S. Atchariyawut, J. Phattaranawik, T. Leiknes, and R. Jiraratananon, "Application of ozonation membrane contacting system for dye wastewater treatment," Separation and Purification Technology, vol. 66, no. 1, pp. 153-158, 2009.

[45] C. Picard, A. Larbot, F. Guida-Pietrasanta, B. Boutevin, and A. Ratsimihety, "Grafting of ceramic membranes by fluorinated silanes: hydrophobic features," Separation and Purification Technology, vol. 25, no. 1-3, pp. 65-69, 2001.

[46] P. Janknecht, P. A. Wilderer, C. Picard, and A. Larbot, "Ozonewater contacting by ceramic membranes," Separation and Purification Technology, vol. 25, no. 1-3, pp. 341-346, 2001.

[47] A. J. Burggraaf and L. Cot, "Fundamentals of inorganic membrane science and technology," in Membrane Science and Technology, A. J. Burggraaf and L. Cot, Eds., p. 3, Elsevier, 1996.

[48] M. Kukuzaki, K. Fujimoto, S. Kai, K. Ohe, T. Oshima, and Y. Baba, "Ozone mass transfer in an ozone-water contacting process with Shirasu porous glass (SPG) membranes-a comparative study of hydrophilic and hydrophobic membranes," Separation and Purification Technology, vol. 72, no. 3, pp. 347356, 2010.

[49] P. V. Shanbhag, A. K. Guha, and K. K. Sirkar, "Membrane-based ozonation of organic compounds," Industrial and Engineering Chemistry Research, vol. 37, no. 11, pp. 4388-4398, 1998.

[50] S. Heng, K. L. Yeung, M. Djafer, and J.-C. Schrotter, "A novel membrane reactor for ozone water treatment," Journal of Membrane Science, vol. 289, no. 1-2, pp. 67-75, 2007.

[51] R. H. S. Jansen, J. W. de Rijk, A. Zwijnenburg, M. H. V. Mulder, and M. Wessling, "Hollow fiber membrane contactorsa means to study the reaction kinetics of humic substance ozonation," Journal of Membrane Science, vol. 257, no. 1-2, pp. 48-59, 2005.

[52] C. Baus, H. Hung, F. Sacher, M. Fleig, and H.-J. Brauch, "MTBE in drinking water production-occurrence and efficiency of treatment technologies," Acta Hydrochimica et Hydrobiologica, vol. 33, no. 2, pp. 118-132, 2005.

[53] E. Drioli, A. Criscuoli, and E. Curcio, Membrane Contactors: Fundamentals, Applications and Potentialities, Elsevier Science, 2011.

[54] L. Pawlowski, "Standard methods for the examination of water and wastewater, 18th edition: Arnold E. Greenberd, Lenore S. Clesceri, Andrew D. Eaton (Editors) Water Environment Federation, Alexandria, USA, 1992; 1025 pp; US\$120 (Hardcover); ISBN 0-87553-207-1," Science of The Total Environment, vol. 142, no. 3, pp. 227-228, 1994.

[55] T. Leiknes, J. Phattaranawik, M. Boller, U. Von Gunten, and W. Pronk, "Ozone transfer and design concepts for NOM decolourization in tubular membrane contactor," Chemical Engineering Journal, vol. 111, no. 1, pp. 53-61, 2005.

[56] T. Dolan, P. Howsam, D. J. Parsons, and M. J. Whelan, "Is the EU drinking water directive standard for pesticides in drinking water consistent with the precautionary principle?" Environmental Science and Technology, vol. 47, no. 10, pp. 49995006, 2013.

[57] J. L. Acero, U. Von Gunten, and K. Stemmler, "Degradation kinetics of atrazine and its degradation products with Ozone and OH radicals: a predictive tool for drinking water treatment," Environmental Science and Technology, vol. 34, no. 4, pp. 591597, 2000. 
[58] F. Xiong and N. J. D. Graham, "Rate constants for herbicide degradation by Ozone," Ozone: Science \& Engineering, vol. 14, no. 4, pp. 283-301, 1992.

[59] J. L. Acero, S. B. Haderlein, T. C. Schmidt, M. J.-F. Suter, and U. Von Gunten, "MTBE oxidation by conventional ozonation and the combination ozone/hydrogen peroxide: efficiency of the processes and bromate Formation," Environmental Science and Technology, vol. 35, no. 21, pp. 4252-4259, 2001.

[60] J. Sutherland, C. Adams, and J. Kekobad, "Treatment of MTBE by air stripping, carbon adsorption, and advanced oxidation: technical and economic comparison for five groundwaters," Water Research, vol. 38, no. 1, pp. 193-205, 2004.

[61] A. Safarzadeh-Amiri, " $\mathrm{O}_{3} / \mathrm{H}_{2} \mathrm{O}_{2}$ treatment of methyl-tert-butyl ether (MTBE) in contaminated waters," Water Research, vol. 35, no. 15 , pp. 3706-3714, 2001. 

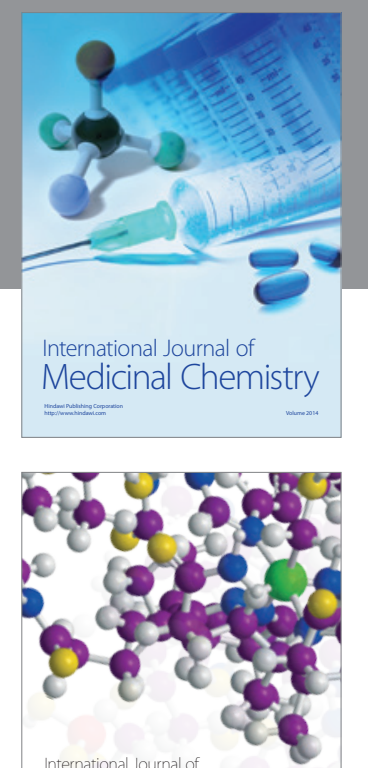

\section{Carbohydrate} Chemistry

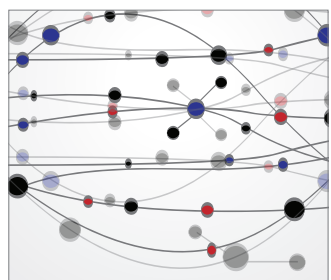

The Scientific World Journal
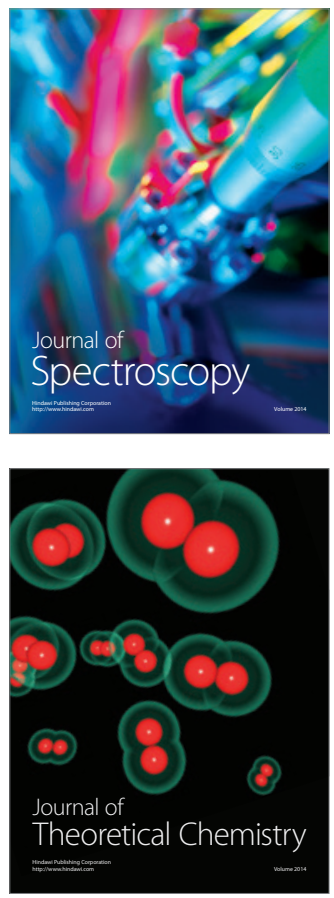
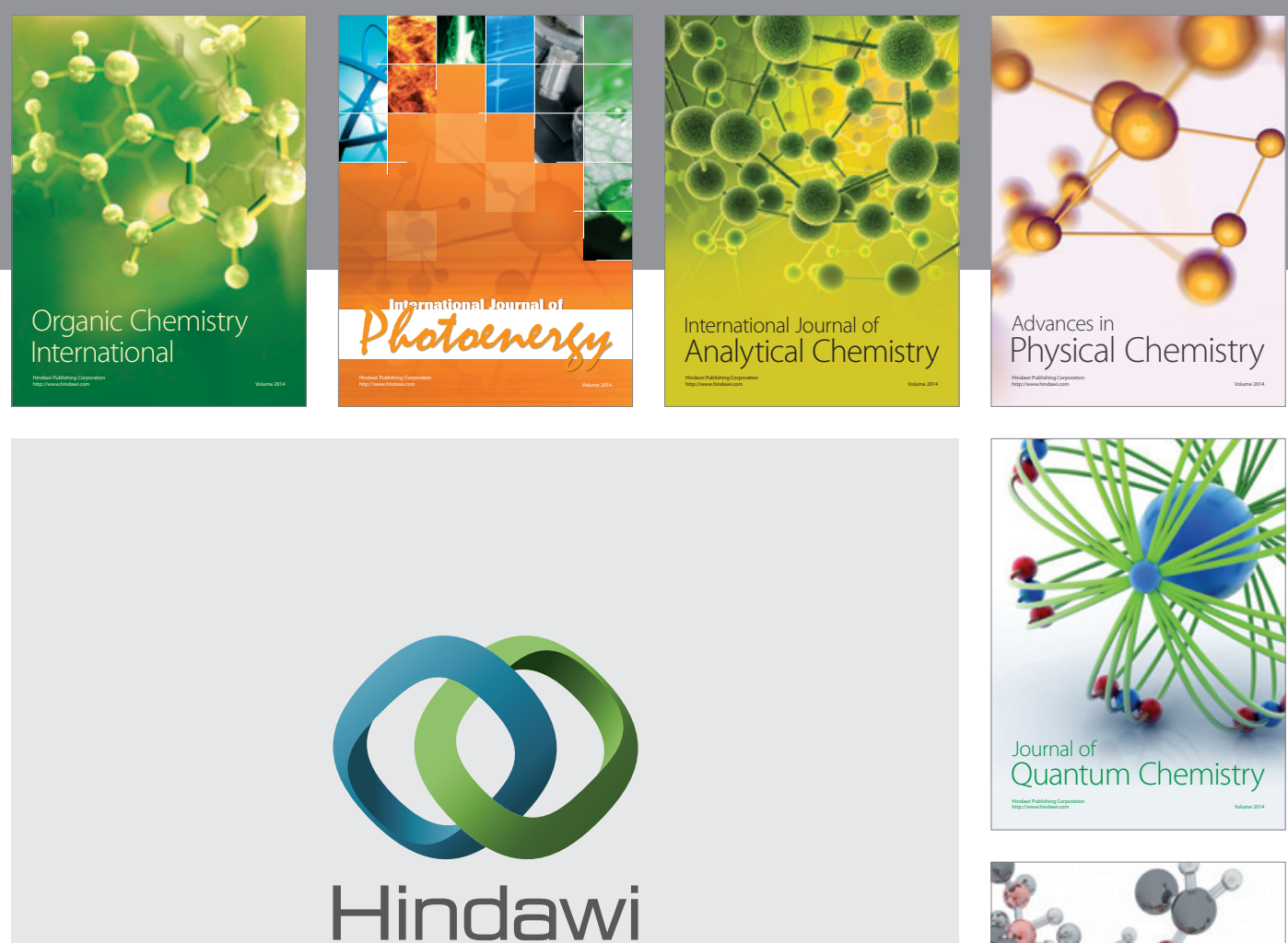

Submit your manuscripts at

http://www.hindawi.com

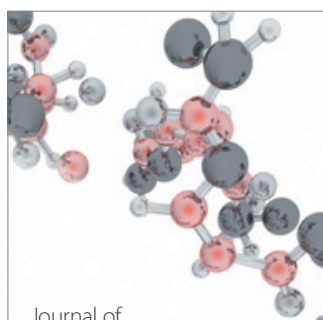

Analytical Methods

in Chemistry

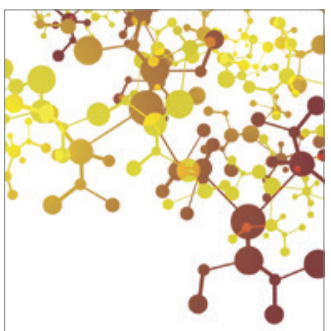

Journal of

Applied Chemistry

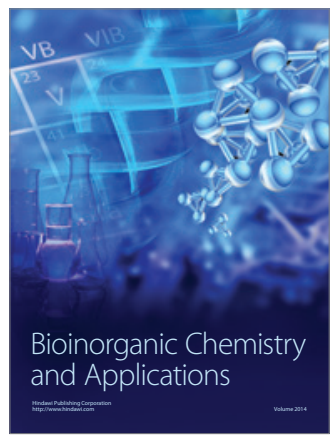

Inorganic Chemistry
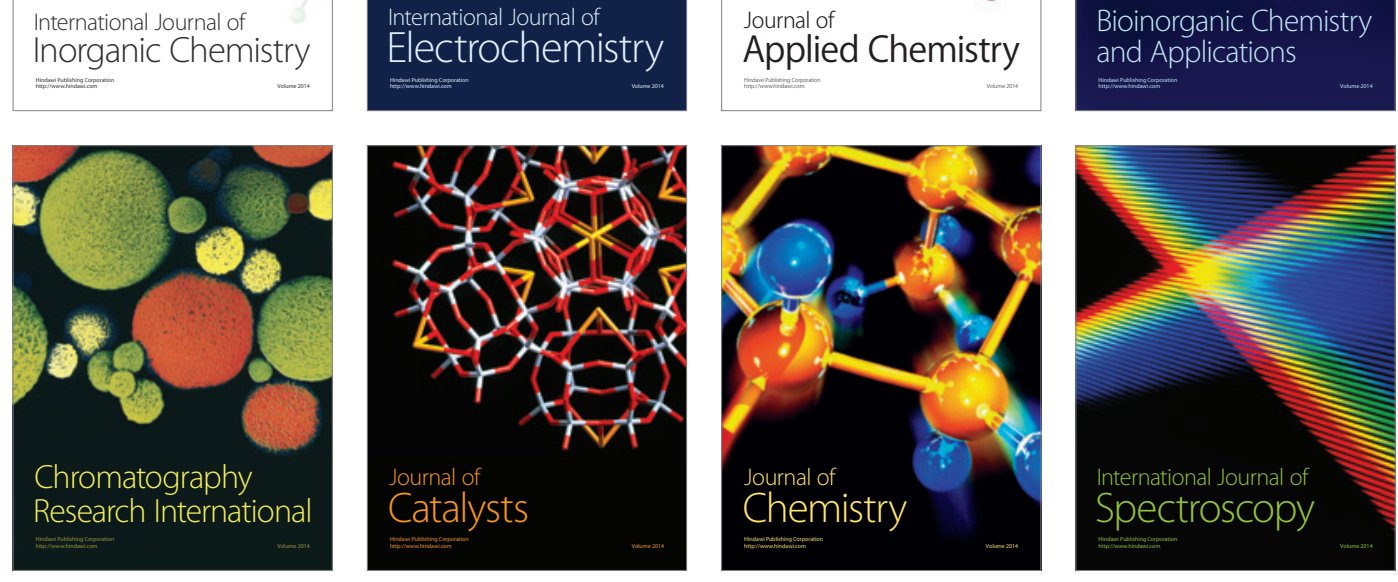